\title{
Perceptions of the Victimization of Individuals with Intellectual Disabilities
}

\author{
Douglas N. Evans ${ }^{1,2}$ \\ ${ }^{1}$ Department of Social and Behavioral Sciences, Mercy College, Dobbs Ferry, USA \\ ${ }^{2}$ Research and Evaluation Center, John Jay College of Criminal Justice, New York, USA \\ Email: devans7@mercy.edu
}

Received March $3^{\text {rd }}, 2013$; revised April 5 ${ }^{\text {th }}, 2013$; accepted April 13 ${ }^{\text {th }}, 2013$

\begin{abstract}
Copyright (c) 2013 Douglas N. Evans. This is an open access article distributed under the Creative Commons Attribution License, which permits unrestricted use, distribution, and reproduction in any medium, provided the original work is properly cited.
\end{abstract}

\begin{abstract}
Perceptions of the victimization of persons with intellectual disabilities were explored from the perspectives of adults with mild intellectual disabilities as well as service providers and supervisors who work with this population. Interviews were obtained for 10 adults with intellectual disabilities. Additionally, those who work with persons with intellectual disabilities were interviewed: 10 service providers and five supervisors $(n=25)$. Results indicate that perceptions of victimization were influenced by factors such as victimizer motivations, proximity to victimization, and situational pre-dictability. Offenses that cause harm are recognized as victimization by most, but non-harmful offenses are not always perceived as victimization, especially when respondents were involved in the offense. The implications of these findings related to recognition, reporting, and prevention of victimization are discussed.
\end{abstract}

Keywords: Intellectual Disability; Victimization; Vulnerability; Perception

\section{Introduction}

The victimization of individuals with intellectual disabilities (ID) historically has received modest research attention, limiting insight into the extent of the problem. This could partly be attributed to the fact that few crime statistics exist for this population, but there is considerable evidence that crimes against persons with ID are systematically underreported. The limited existing research and statistics on persons with ID indicate that estimates of the prevalence of victimization of this population vary extensively (Horner-Johnson \& Drum, 2006), making it difficult to determine the extent of the problem.

The ambiguity surrounding definitions of victimization and crimes involving individuals with ID facilitates and promotes underreporting of the problem. Acts of victimization against persons with disabilities often are labeled as "incidents" rather than crimes. In many cases, incidents are handled internallythrough internal organizational means if the act occurs in a supported living context-rather than through the criminal justice system (Petersilia, 2001). That individuals with ID may not realize they are being victimized compounds the problems associated with defining acts of victimization (Marge, 2003). Individuals with ID may not recognize victimization because mental impairment precludes their ability to identify it or because victimization has been a part of their lives for many years.

This research utilizes a case study approach to qualitatively explore victimization of individuals with ID in a supported living context from the perspectives of individuals with ID as well as service providers and supervisors who work with this population. The site of analysis is a typical supported living organization, and the objective of this research is to enhance comprehension and awareness of victimization of individuals with ID. Because national statistics regarding crimes against individuals with ID are problematic, this study seeks to contribute to the issue through a local-level analysis. While victimization of any kind demands awareness, because some disabilities create a need for assistance with daily activities (Nosek, Foley, Hughes, \& Howland, 1997) and because of the difficulty that persons with ID often face in recognizing, reporting, and responding to the range of acts of victimization, the population of persons with ID requires special attention.

Defining victimization in a consistent manner is no easy task. Quinney (1974) asserts that the concept of "victim" is a social construction, thus, defining what constitutes victimization is an inherently subjective process that depends on the target's perception of the act. In other words, one person may perceive a physical confrontation between two people to be "horseplay" or justifiable punishment while another may perceive the same act to be excessive abuse and consider it victimization. This distinction is crucial because it can trigger a victim's or a witness's inclination to respond to or report the instance as victimization.

Scholars have defined victimization in a variety of different ways. A study on the relationship between gender, victimization, and outcomes resulting from victimization defined victimization as interpersonal aggression, which is a deliberate intention to cause physical or psychological harm that leads to a negative encounter between two individuals (Pimlott-Kubiak \& Cortina, 2003). Other research has limited the definition to criminal victimization, which focuses on physical harm and excludes emotional, mental, and verbal abuse as well as social and economic exploitation (Hiday, Swartz, Swanson, Borum, \& Wagner, 1999). In research on sexual victimization, the term was 
defined as unwanted sexual contact (Marx, Calhoun, Wilson, \& Meyerson, 2001). Scholars have offered a broader characterization in the context of school bullying, defining victimization as conflict between group goals (Bukowski \& Sippola, 2001). These definitions reveal that victimization can be marked by a potentially limitless number of subjectively determined characteristics, which makes it a difficult term to describe consistently.

Defining victimization may be even more difficult when the victim has an intellectual disability. In the realm of disability, terms such as abuse, neglect, and harassment are referenced interchangeably, suggesting that victimization involving persons with disabilities is not clearly defined (Sin, Hedges, Cook, Mguni, \& Comber, 2009). While there is some degree of ambiguity inherent to instances of possible victimization involving this population (e.g., physical punishment vs. abuse), the larger concern is the reaction that the definition triggers. For the purposes of this study, the following description of victimization is used, extending Sin et al.'s (2009) definition: acts involving physical, sexual, verbal, and emotional violence as well as instances of harassment, abuse, neglect, and financial manipulation or exploitation.

Intellectual disability is characterized by three attributes: limitation in intellectual functioning and adaptive behaviors; intelligence quotient (IQ) between 70 and 75; and an onset of disability before age 18 (The Arc, 2012). According to the President's Committee for People with Intellectual Disabilities (Administration on Intellectual and Developmental Disabilities), there are seven to eight million Americans with ID. Furthermore, ID affects one in ten families. Research indicates that individuals with ID face an increased risk for being victimized compared to people without ID (Petersilia, 2001). In addition to increased risk, although exact statistics vary, this population experiences the highest rates of victimization of any disability category both nationally and internationally (Rand \& Harrel, 2009; Wilson \& Brewer, 1992).

There is a lack of detailed information on the victimization persons with disabilities. Statistical sources conflict with one another because methods of data collection and reporting do not disaggregate between victims based on their specific disability type nor do they include details on crimes against this population. A comparison of federal Hate Crimes statistics and National Crime Victimization Survey (NCVS) data on the victimization of persons with disabilities illustrates the wide variation between data sources. In 2009, federal statistics indicated that there were 99 hate crime incidents involving victims with a disability (US Department of Justice, 2009). However, NCVS reports indicated that there were more than 750,000 violent victimizations committed against persons with a disability in 2009 (Harrell, 2011). The discrepancy between the two sources could indicate a number of issues, including a high degree of non-reporting to law enforcement, lack of evidence to corroborate reported victimization, or prosecutorial failure to file charges due to lack of substantiation or inability of a victim to answer questions and testify in court. Importantly, while NCVS reports break down the statistics by disability type, the federal Hate Crimes statistics do not include information on disability type. Outside of Hate Crimes statistics, official data on the victimization of persons with disabilities are nearly non-existent. Petersilia (2001) emphasized the absence of any recurring collection of information on crime victimization of persons with disabilities at the national, state, or local level. In part due to this lack of data, it is difficult to ascertain the extent of victimization against persons with ID.

There are several reasons for the dearth of data on victimization involving individuals with ID. There is a low rate of reporting of incidents involving this population. Research indicates that the severity of ID affects a victim's likelihood of first identifying, and then reporting when victimization has occurred. The rate of reporting decreases when the individual is considered to have more severe intellectual disabilities (Wilson \& Brewer, 1992; Sobsey \& Doe, 1991). Other reasons why persons with ID do not report victimization include a lack of knowledge on how to report, low self-esteem, inability to communicate, fear of personal harm if they report, and conflicts of interest between victims and perpetrators in the instance of maltreatment at the hands of service providers or family members (Petersilia, 2001; Muccigrosso, 1991).

There are a number of possible types of victimization that persons with ID could experience, including physical violence, sexual assault, verbal and emotional abuse, school and cyber bullying, property damage, discrimination (Sin et al., 2009), neglect, psychological abuse, financial exploitation, withholding of medication, and inhumane treatment, depending on how the victim, the perpetrator, and any outside witnesses perceive and react to these incidents. The wide range of potential acts of victimization, in addition to preconceptions and prior experiences that influence the perceptions of victims and observers, compound the difficulty of accurately identifying ambiguous acts as victimization, particularly when the intent of the perpetrator is indiscernible.

The relationship between ID and risk for victimization has become progressively more visible since the Independent Living Movement of the 1970s, in which persons with disabilities pushed for the removal of social barriers that prevented them from living independently in the community (DeJong, Batavia, \& Meknew, 1992). Prior to the Independent Living Movement, many persons with disabilities were housed in institutions (Sobsey, 1994), but in recent decades, independent living centers have opened across the country to provide community-based integration and supported living services to individuals with physical, developmental, and intellectual disabilities. The shift from institutionalization to community-based supported living has created a new realm through which to explore the victimization of this population.

Several studies have explored the victimization of individuals with disabilities who receive personal assistance services. Paid service providers offer invaluable support services and assistance with daily tasks, and they are uniquely positioned to identify signs of and report victimization because of their frequent contact with clients (in this paper, clients refers to individuals with intellectual disabilities receiving supported living services). However, in some instances, personal assistance providers may use their position to victimize their clients physically, verbally, or financially (Oktay \& Tompkins, 2004). Intellectual disabilities are associated with increased exposure to sexual abuse and a greater use of force and violence at the hands of service providers (Powers, Curry, McNeff, Saxton, Powers, \& Oschwald, 2008).

This work was inspired by years of exposure to and work alongside countless clients with various disabilities and capabilities and staff with wide-ranging backgrounds that brought them to employment in supported living. Supported living offers obvious benefits to clients-social and financial support, 
positive relationships, and assistance with daily tasks — and less evident problems, including manipulation, use excessive of force, and disrespect of individual rights.

Research has addressed the victimization of individuals with disabilities at the hands of service providers, but limited research has examined the perception and comprehension of victimization from the perspectives of these individuals and those who work with them. The following was the primary research question: how do persons with ID and those who work with them perceive and comprehend victimization? This study seeks to identify areas of intersection and differentiation between these two groups in terms of their recognition of victimization. The hope is that this research will enhance awareness of the intersections between ID and victimization in order to improve the safety and wellbeing of clients in supported living environments.

\section{Method}

Qualitative methodology was selected for this study to ascertain detailed perceptual information regarding victimization of individuals with intellectual disabilities. Qualitative research is advantageous when there is limited existing knowledge about an issue; it also is helpful in regards to individuals with ID because unlike survey research, interviewing can enhance a researcher's ability to detect inconsistencies in participant responses, and it enables researchers to provide clarification in the event that a respondent is confused about a question (Loberg, 2009).

This research was conducted over the span of several years. The author worked in a supported living organization (study site) for six years, and during that time conducted informal and formal interviews as well as observational research. Selection of respondents was not easy because of the potential for conflict between clients, service providers, and supervisors regarding possible reports of victimization, possibly perpetrated by others in the organization. To minimize this conflict, the researchers asked respondents to not use any names during interviews.

According to supervisor respondents, the supported living organization is similar to other large supported living organizations in terms of mission (client-focused), number of clients (2000) and staff (500), and varieties of disability types receiving services. Thus, this organization appears to provide an adequate representation of large supported living centers around the country.

\section{Respondents}

The populations of interest in this study consisted of adults with ID as well as service providers and supervisors who work with individuals with ID. Purposive sampling was used to select respondents who were at least 18 years old and receiving (individuals with ID) or providing (service providers and supervisors) services through a supported living organization.

The first group was selected with the assistance of a case manager at the supported living organization, who identified individuals with ID that met the following criteria: 1) receiving supported living services through the supported living organization for a minimum of six months; 2) assessed as having an IQ in the range of $70-75$; and 3) 18 years or older. This resulted in a sample of 14 individuals. Three individuals refused to participate and another had a communication deficit that would have made interview comprehension difficult.
The final sample consisted of 10 adults with ID (nine males, one female). Two respondents had a dual diagnosis, meaning that in addition to ID, they had other diagnoses, and in both cases these were psychotic disorders. Respondents with ID ranged in age from 28 to 70 years with a mean age of 47 . Seven respondents lived alone, two were roommates, and one lived with a spouse. All of the respondents functioned at a high enough level to qualify them for semi-independent living without 24 hour staffing. Respondents received anywhere five to 60 supported living service hours per week from service providers, with an average of 24 hours per week across all 10 respondents.

Nine respondents reported working at least part-time. Jobs duties included custodial work, food service, laundry, and car washing. Respondents' daily routines appeared to revolve around their work schedule and also consisted of various activities with service providers. Commonly reported activities included errands to the bank, grocery store, gym, or library as well as outings to the movies, parks, malls, and social gatherings with others from the organization. Most took the bus to work while others received transportation from their service providers. Most respondents preferred to spend their free time relaxing at home and watching television, but a few respondents enjoyed going out in the community as much as possible.

The next group consisted of service providers and supervisors at the supported living organization. The same case manager at the organization informed service providers and supervisors about the study, and if interested, instructed them to contact the research team. The criteria for their participation included: 1) current employment in supported living as a service provider or supervisor and 2) a minimum of six months experience in one's current position.

The sample consisted of 10 service providers (six male, four female) and five supervisors. Age of this sample ranged from 24 to 51 with a mean of 30 . Service providers had experience in supported living employment ranging from six months to seven years. The five supervisors were all females and had experience ranging from three to 18 years of employment in supported living. Service providers had no connection with respondents with ID. In other words, service providers did not work directly with any individuals with ID who were interviewed for this study. Supervisors did have previous associations with many of the respondents with ID on their caseloads, but they were kept unaware of who was interviewed for this study. Because all respondents were instructed not to use identifying names of any clients or employees at the organization during interviews, the extent of overlapping information between respondents with ID and supervisor respondents was unknown.

\section{Procedure}

Prior to conducting interviews with individuals with ID, service providers, and supervisors, the principle researcher met briefly with all respondents who expressed interest in the study in order to make introductions, explain the purpose of the research, and establish familiarity with respondents.

Interviews with respondents with ID were conducted in their homes or places in the community that afforded sufficient privacy (e.g., a quiet park, private study room in a public library). Interviews with service providers and supervisors were conducted in a private room at their place of work or at a location in the community that afforded privacy. Initially, respondents were provided with an informed consent, which was read aloud. Respondents also were notified that participation was voluntary, 
and they could stop the interview at any time. Each respondent provided both oral and written consent. Following the consent process, semi-structured interviews commenced.

Two interview guides were used to conduct interviews. The same interview guide was used for service provider and supervisor respondents. The principle investigator, who has several years of experience and training working and communicating with individuals with ID, conducted each interview. Interviews were audio recorded.

Interviews with respondents with ID lasted between 45 and 150 minutes. Questions for respondents with ID were adapted from the Attendant Mistreatment Interview Schedule (Oktay \& Tompkins, 2004) and included items about understanding, recognition, and experiences with physical abuse, sexual abuse, verbal abuse, theft, neglect, and extortion. Oktay and Tompkins (2004) asked about these forms of victimization in relation to respondents' service providers ("Has your [service provider] ever taken anything from your home, or taken money from you without permission?"). In the present study, respondents were not asked about specific victimizers unless they first introduced them through their responses. Additional question items included perceptions of neighborhood safety, encounters with strangers, definitions of victimization, and sources of knowledge about victimization. Interviews were semi-structured to allow the interviewer to clarify questions by asking them in different ways and to use examples to better illustrate topics ("How safe is your neighborhood?" followed by, "How safe would you feel walking around your neighborhood after dark?”). Due to the sensitive nature of some questions, the supported living organization agreed to allow the research team to offer its counseling services to respondents who showed signs of distress. Fortunately, no respondents expressed discomfort or requested follow-up counseling, even after such services were offered.

Interviews with service providers and supervisors lasted between 25 and 90 minutes. Interview items for service providers and supervisors included questions regarding the nature and extent of their training in identifying and responding to victimization; specific experiences with or knowledge of victimization of individuals with ID; understanding of the range of victimization of individuals with ID; and the process of defining ambiguous instances as victimization or non-victimization.

\section{Data Analysis}

Data analysis began during initial observations and continued through the data collection phase. Immediately after interviews, the researcher's comments, reactions, and interpretations of each respondent's interview were recorded. Following the process of interview transcription, responses were grouped according to broad themes. Two additional researchers not directly involved in the interview process reviewed each transcript separately and grouped the information into themes. In the event of disagreement regarding coding decisions, the three researchers discussed proposed groupings in relation to written interview notes until reaching consensus. Following the coding process, transcripts were reviewed to identify key passages and informative quotes that could be used in the research write up (Basit, 2003).

\section{Results}

The objective of this research was to address the nature of victimization of individuals with ID through an exploration of commonalities and the extent to which perceptions of victimization vary among individuals with ID, service providers and supervisors. Responses were categorized based on themes that best illustrated the similarities and differences amongst perceptions of individuals with ID, service providers, and supervisors in regards to victimization (Merriam, 2002). The themes included: definitions of victimization, victimizer motivations, proximity to victimization, and situational predictability.

\section{Definitions of Victimization}

All respondents were asked to discuss examples-either actual or possible — of victimization involving individuals with ID to assess their subjective understanding of what constitutes victimization of this population. Because a few respondents with ID were not familiar with the term victimization, we also asked for their descriptions of crime. Regardless of whether they discussed "victimization" or "crime", many respondents with ID listed television shows (e.g., Andy Griffith; Law and Order) and news media as sources of their understanding of victimization and crime. Each respondent mentioned at least one of the Part I index crimes listed in the FBI Uniform Crime Reports (UCR), which indicated some commonality amongst definitions of victimization across all respondents. Respondents with ID referenced specific offenses: stealing, robbery, breaking and entering, murder, rape, assault and battery, and drug dealing, citing economic crimes (e.g., robbery, theft) most frequently. Service providers and supervisors cited sexual assault most frequently.

Sandy was a supervisor with five years of experience in various supported living positions. She often went out of her way to help her clients, was devoted to her work, and quickly worked her way up to supervisor. Sandy thoroughly discussed her organization's definition of the range of victimization against individuals with ID:

Physical abuse is willful infliction of injury, unnecessary physical or chemical restraints or isolation, and punishment resulting in physical harm or pain. Sexual abuse includes all allegations of rape, sexual misconduct, or sexual exploitation. Verbal abuse includes oral, written, or gestured language that includes disparaging and derogatory remarks to clients, and mental abuse includes unreasonable confinement or intimidation, and any punishment or action that is intended to cause shame, embarrassment or intimidation ... Neglect includes failure to provide appropriate care, food, medical care, or supervision. This includes when family or staff are not following physicians' orders ... We are also trained to recognize exploitation. This can be financial-any deliberate misplacement, exploitation, or wrongful temporary or permanent use of an individual's belongings or money-or can include any situation in which the client is used for financial gain, labor or sexual exploitation.

Some respondents, particularly service providers and supervisors, expressed a lower threshold for defining an act as victimization. Codis, a service provider with more than seven years of experience who took his work seriously, used broad criteria to determine whether an act constitutes victimization:

I see [victimization] as the clerk at Kroger looking at [my clients] differently, so I see victimization, discrimination, 
maltreatment, every day and all over the place. My eyes are always open and I take it to heart whenever I see something like that happen.

Jean was a supervisor with 20 years of experience in supported living and was a favorite of her clients because of her kind and positive attitude. She asserted that victimization involving individuals with ID is broader than traditional legal definitions of victimization:

There have been a couple of [clients with ID] who were verbally abused by a bus driver who was making sexual comments to them. It is discrimination when someone targets a person because of their disability. This offense would probably not be punished in a court of law but it is certainly victimization no matter who the victim is.

A few respondents with ID described instances in which they were victimized verbally. Lynn, a 47 year-old client with ID who prided himself on his critical thinking and his awareness of other peoples' behaviors, said:

People have said hurtful things to me. I've been called dumb or stupid by some people that I knew. I responded kind of badly. Sometimes I get mad, but I try to relinquish that. I don't like to be called a freak just because I don't fit in. It makes me feel inferior. I try to avoid [people that would insult me].

Michael, a 33 year-old client with ID with a noticeable speech impairment and a kind and outgoing demeanor, also spoke about what he believed to be verbal abuse: "People at work make fun of me, say mean things to me. They make fun because I get shaky. I just try to ignore them.” Several respondents with ID could not offer specific examples but discussed feeling as if they are treated differently or "looked at funny" because of their intellectual disability. Betsy, a 47 year-old client with a calm and quiet disposition, said, "Sometimes I can feel people looking at me because [of my disability]". Elmer, a 56-year old respondent with ID who did not work and enjoyed spending his time riding city buses and sitting on park benches to watch people walk by, mentioned the different ways people in the community respond to his disabilities (in addition to ID, he walks with a limp in his right leg). "I think people do act different toward me because of [my disabilities], like they think I'm this way because of drinking or drugs. But some people are nicer to me when they see notice [my disabilities]."

A few respondents suggested that definitions of victimization and crime should account for the fact that the victim has an intellectual disability. Lynn stated:

Some [people with ID] need extra protection. There's a lot of things that they're very good at and capable of, but there's a lot of things about the world that they don't quite understand. The people that do understand them, they'll take advantage of that. I guess a person can use their knowledge in the wrong ways, try to get them to believe what they're saying when they're not really truthful. But there are a lot of people [with ID] that know the game and they don't get fooled that well.

Bill, a service provider with one year of experience who worked while attending school and appeared to be very considerate of his clients, asserted that a victim's ability to recognize and comprehend victimization are necessary skills, but their ability to communicate is of equal import. If they cannot speak, their likelihood of making a report drops considerably:

There's a lot of clients that can't communicate so there's no way for them to report victimization ... A lot of the clients that can't communicate have a staff with them 24/7 so that if they were abused by someone, [the service provider] would always have their eye on the client. But the problem is if a person is hired who doesn't have a strong moral background and takes advantage of the client, I don't think there is any way that anybody would ever find out... If there's only the two of them then there's no way that anyone outside could ever find out what happened between those two.

The majority of service provider and supervisor respondents, as well as a few respondents with ID, discussed how their particular vulnerabilities widen definitions of victimization involving individuals with ID. Several respondents stated that this population is vulnerable to victimization as a result of a number of factors associated with ID, as Sandy discussed:

[Clients with ID] are sometimes more vulnerable due to their lower level of cognitive functioning, lack of knowing how to protect themselves, inability to differentiate between the intentions of other people, having small support systems, the inability to know who to go to for help, and possible isolation if they are unable to communicate or are not mobile.

\section{Victimizer Motivations}

Several respondents drew attention to the influence of perpetrator motivations on perceptions of acts that could be construed as victimization. Some supervisors stated that motives have minimal bearing on determinations of victimization. For instance, Jean said, "If the person is harmed in any way, then regardless of intent [that is victimization]. We would definitely take action in that case.” Other supervisor respondents noted the importance of victimizer motivation as a factor that could enhance the perpetrator's culpability. Sandy said:

I know of several clients who were taken advantage of because the offending party knew they either did not have the cognitive ability to understand what was taking place, were unable to communicate to others, or were intimidated or isolated from other individuals. These are the people we should be most concerned about because they prey on vulnerability.

The awareness of potential motivations for committing acts of victimization against individuals with ID is necessary for someone to perceive ambiguous acts as victimization. This is especially true when victimizers are closely associated with individuals with ID, either as family or friends. Baka, a service provider with eight years of experience who had laid back interactions with his clients, noted the potential for "friends" to take advantage of individuals with ID:

[Clients with ID] are more easily manipulated by somebody who pretends to be a friend. I've known circumstances where people have abused that friendship by getting money out of these clients and not paying them back, pretending to be a good friend but they're just using them, and once they get their money, they disappear until they 
want more money. I've seen that happen before.

Flina, a service provider with five years of experience who was working her way through school and planning on pursuing other jobs after her graduation, discussed a similar scenario involving financial exploitation in which the perpetrators used their power over the individual with ID to manipulate him:

It's usually about money. People with intellectual and developmental disabilities have a tendency to be targeted. A lot of stories I've heard are when a person will lure them in and say "come live with me" and then they take all of their social security money. A certain [client] was found playing the tambourine in front of Target, and the people who were caring for him were taking his social security money and making him play the tambourine for [additional] money.

PJ, a 52 year-old client with ID who enjoys sports, taking walks, and eating out, expressed his awareness of the financial motivations of potential victimizers, but he limited his discussion to strangers: "I know what homeless people want when they come up to me on the street. It's always about money, but I never give it to them.”

Perpetrator motivations and intentions are not always easy to infer. Trina, a service provider who in four years had worked her way from substitute to service provider and has since become a supervisor, discussed the difficulty of determining motivation, particularly when an act is interfamilial:

It seems if something were to occur within their immediate family, the motivation may be a control issue. They feel like since they're family it's not as bad when they take advantage of [a family member with ID] because they are related. They feel like [the family member with ID] can't fend for themselves and like it's their job to do so but they don't do it in the most appropriate way. It's difficult to know if the family member is being forceful or trying to take advantage of the person. Who's to say?

\section{Proximity to Victimization}

Proximity to acts of possible victimization had a noticeable impact on respondents' perceptions, responses to, and likelihood of reporting acts of victimization. Involvement in an act, or lack of involvement, appears to influence how it is perceived. Respondents not directly involved in a particular act, either as a victim or a perpetrator, were more likely to perceive an ambiguous act as victimization than those involved in an act. For example, Joey, a service provider with five years of experience, identified an encounter he witnessed between another service provider and a client as "forced medication"-grounds for employment termination-rather than "medication error", which would require the service provider to fill out an incident report and participate in additional training. Baka discussed an incident he heard about in which another service provider locked a client in the client's room. Baka perceived this as "forced confinement”, which also could lead to termination. However, he noted the ambiguity that service providers are allowed to utilize "time outs" when clients become difficult. Time-out is an acceptable form of punishment as long as clients are not physically restrained, there is behavioral justification for the time out, and it is consistent with the client's behavior plan.

Those directly involved in a questionable act of victimization were less likely to perceive it as victimization. Elmer spoke about an instance in which he gave $\$ 40$ to a stranger in the mall for a magazine subscription, which he never received. Initially, he did not perceive this as victimization: "I didn't think there was anything wrong with giving [him my money] at first.” But after discussing the incident during the interview, Elmer connected this incident to similar experiences and realized his mistake: "Strangers have asked me for money two or three times before. I know I'm supposed to say no. [This last time] I felt taken advantage of, but it was my fault for giving him my money. I should have just walked away.” He was unable to see that he was being financially exploited at the time of the act. A later interview with a supervisor revealed that she witnessed a carnival worker's attempt to cheat Elmer out of at least $\$ 25$ by overcharging him for a t-shirt.

Flina discussed an instance that involved two forms of victimization. She was both a victim and a witness, but she only described one as an act of victimization:

[A client with severe ID] was hitting me repeatedly because I was trying to pass his meds, so I stepped back and I was going to give him a few minutes to calm down. This other staff person proceeded to take the meds out of my hand, pushed the client's head back into a chair while his arms were flailing and poured the pills down his throat ... I reported it, but it was me against her, and no one could prove that it happened.

Although Flina perceived the forced medication as victimization, she did not believe that she was victimized by her client's physical assault. Her reasoning was, "[There was] no intent to hurt me. He just didn’t want to take his meds. Sometimes getting hit is part of this job."

\section{Predictability}

Several respondents drew attention to the importance of predictability in the lives of individuals with ID. When their routines are predictable, it is easier to detect when a situation requires caution or concern. When a context is foreign, it could create uncertainty for individuals with ID. Trina discussed problems associated with unfamiliarity in novel contexts:

[Clients with ID] who are outside of their usual environment would be at a big risk for victimization. If they were traveling in a different city or were in a new environment, they might be easily confused and taken advantage of, especially if they are alone and there is no advocate to warn them about harmful situations and stand up for them.

Individuals with ID expressed concern about unpredictable situations. A few respondents with ID mentioned feeling anxiety and worry whenever they are around "drunks" or people who are homeless. PJ spoke about his concern around such persons: "I was at Subway getting my lunch and there was this homeless guy. I think he was drunk. It made me nervous [because] I thought he might try to take my money or hurt me.” PJ said that to be safe, he avoids unfamiliar situations unless a family member, service provider or friend accompanies him. When he is alone, he tends to frequent places that he has been to many times because, "I've been there before. I know what to expect." Elmer also said that homeless people worry him because "I carry some money but I'm careful with it. I don't want 
a homeless person to rob me, take my billfold and run away with it. They beg and ask me for money but I never give it to them."

The issue of predictability emerged when respondents with ID spoke about encounters with strangers. Some asserted their belief that it is acceptable to talk to strangers, but only in controlled situations (e.g., on the bus, while at work). However, some respondents with ID noted certain factors that they consider before engaging with a stranger. Lynn said, "It depends on the person's age [and] it depends if the person is friendly." Elmer said, "If a stranger says hi to me, I like to be friendly with them." Other respondents with ID are more skeptical of stranger encounters. Betsy said, "I don't talk to strangers because you never know who you can trust." Michael said, "It is not okay to talk to strangers because all they want is your money.” Respondents appeared to base their discussions on personal experience. Those who had positive and friendly prior contact with strangers were more likely to be open to communicating with strangers in certain situations compared to those who had negative prior encounters with strangers (e.g., someone asking them for money).

Some respondents with ID mentioned nighttime as a situation that presents unpredictable possibilities. Many respondents said that they avoid going outside after dark to evade encounters with strangers at nighttime. Lynn discussed the unpredictability of encounters with strangers at night:

When it gets dark out you have to be careful. Some people are dirty. I try to stay away from them, but there's always the chance that I could get attacked by a stranger. If I'm ever out after dark, I just hope and pray that it doesn't happen.

Predictability is an asset, but it also can interfere with recognition of victimization. Individuals with ID typically do not expect significant others in their lives to take advantage of them. Their comfort with family members and friends may cloud their awareness that these persons could potentially victimize them. Carol, a supervisor who was promoted from a service provider after three years of experience but has since left to pursue a career in policy analysis, discussed the possibility that individuals with ID may not recognize victimizers when they are too close to a potential victimizer:

It can be even harder for [individuals with ID] to recognize victimization when coming from someone familiar.

One of the teams I work with has had to closely support a client whose sister always asks her for money or otherwise tries to manipulate her finances, to help the client understand that she can have a positive relationship with her family while not submitting to this exploitation. This has been a very difficult struggle for this person to recognize, understand, and deal with.

According to data from each sample of respondents, victims with ID were usually familiar with their victimizer. Victims were linked to their perpetrators through familial ties, community relationships, or disability support services. The list of reported victimizers included family members, guardians, former or current service providers, co-workers, teachers, other clients with disabilities, bus and taxi drivers, and institutional staff. Strangers were specified as being the perpetrators in very few instances. Although predictability may comfort individuals with ID, it also may distract them from perceiving an incident as victimization.

\section{Discussion}

This study explored how individuals with ID, service providers, and supervisors perceive the victimization of individuals with ID and factors that influence their perceptions. The focus of this study was on persons with ID because this group experiences the greatest risk of victimization in relation to other types of disabilities (Rand \& Harrell, 2009). In discussing definitions of victimization of individuals with ID, most respondents mentioned at least one key component associated with current definitions of victimization involving this population (Sin et al., 2009). However, because Sin's definition is very broad, as expected, there was inconsistency between respondents' subjective definitions of victimization. Variation in definitions of victimization of individuals with ID was particularly evident when respondents discussed whether an ambiguous act (e.g., forced medication, client physically hitting a service provider) constitutes victimization. Research on bullying found similar results; teachers' definitions varied widely, suggesting that determinations of what constitutes bullying is a complex process (Mishna, Scarcell, Pepler, \& Weiner, 2005). We identified key factors that impacted individuals with ID, service providers', and supervisors' perceptions and definitions of victimization: perpetrator motivations, proximity to the incidentincluding whether or not they were directly involved in the incident-and predictability of the context and environment in which the incident took place.

Service provider and supervisor respondents, along with respondents with ID, discussed a range of victimization involving individuals with ID. Intellectual disability appears to widen the scope of victimization involving this population. Although physical, verbal, emotional, and sexual abuse could occur regardless of whether or not a victim has ID, victims with ID are susceptible to other offenses that the general population is not. Similar to young children and the elderly, individuals with ID are subject to neglect at the hands of guardians, caretakers, or service providers, depending on their unique vulnerabilities. Respondents mentioned clients with ID who have been victims of neglect-related incidents, including service providers who slept on the job, failed to change diapers regularly, and committed medication administration errors. Other discussions of victimization incidents involving individuals with ID included forced confinement, forced medication, financial exploitation, having food withheld, medication theft, and forced panhandling, in which an individual with ID was coerced into standing outside of a store to beg for money. These reports suggest that the nature of victimization is more comprehensive when it involves individuals with ID.

The nature of victimization expands when the victim has an intellectual disability because their capabilities and life experiences are inherently different than the general population. In general, people with ID have difficulty processing information quickly and need more time to do so when compared to people without such disabilities. Furthermore, people with ID have trouble making self-protective decisions (Hickson, Golden, Khemka, Urv, \& Yamusah, 1998), resisting coercion (Khemka, Hickson, Casella, Accetturi, \& Rooney, 2009), and their conceptions of potentially dangerous situations are rudimentary (Hill, Lewis, \& Dunbar, 2000). Many respondents noted that the unique vulnerabilities associated with ID influence their 
likelihood of being victimized. Although most respondents, including those with ID, considered this population to be vulnerable in the eyes of potential victimizers, respondents discussed additional factors that motivate victimizers. Individuals with ID tended to believe that victimizers are motivated by financial gain, while service providers and supervisors cited sex and control over the victim as the most common motivations. Financial, sexual, and control motives are consistent with the findings of Petersilia (2001). There are some possible explanations between these differing perceptions of motives. Most respondents with ID receive considerable practice using money because they either work or receive Social Security and have some degree of freedom to spend their own money. They understood that money is a valuable resource and have been taught to be careful and protective of it, especially when strangers ask them for money. The value of money is not difficult for them to comprehend, whereas sexual and control-oriented motivations are less tangible and more complex, especially if they have never been victims of sexual or violent offenses. Service providers and supervisors oversee the financial records and expenditures of clients, so they are less concerned with financial exploitation than with physically or sexually harmful offenses, the visible signs of which are sometimes difficult to detect.

The finding that many respondents with ID learned about victimization from watching television reveals how proximity influences perceptions of victimization. Service providers and supervisors receive considerable on-the-job training in recognizing and responding to signs of victimization, and according to multiple supervisor respondents, clients with ID receive at least annual training in recognizing and responding to victimization (e.g., role playing scenarios, practice calling 911). However, television portrayals of victimization appear to be more memorable than training for those with ID. This can be explained by the high volume of television that viewers watch, and also the amount of violence on television, which is far greater than the amount of real-world violence (Bushman \& Huesmann, 2001). Learning about victimization from watching television, while in some ways informative, is somewhat problematic because it precludes their active interpretation of an event; television show characters or on-air news personalities convey what is and is not victimization. Additionally, learning about victimization as a passive observer does not enable individuals with ID to gain experience responding to it. If television-based learning were supplemented with practical training, this could empower individuals with ID and gradually reduce their risk for victimization.

Although the ability to perceive and be aware of victimization is imperative for individuals with ID, the capacity to communicate it to the proper authorities is equally as important. As many service provider and supervisor respondents noted, when communicative disabilities are apparent in persons with ID, risk is further increased because the likelihood of reporting diminishes drastically, and perpetrators may take advantage of this. An inability to communicate effectively not only reduces the likelihood of reporting victimization but according to supervisor respondents, it also limits their ability to take action and punish the perpetrators of these offenses. While some persons with ID have a better understanding of precarious situations and a higher communicative capacity than others, assessments of the activities and capabilities that they are able to do independently, using instruments such as the Functional Limitation
Screen, would provide a practical measure of the individual risks associated with each individual (Moore, 2000).

Involvement in an act appears to influence perceptions of the act, but not as expected. Respondents not directly involved in a particular act, either as victim or perpetrator, were more likely to perceive an ambiguous act as victimization (e.g., "forced medication" rather than a medication error; "forced confinement" rather than a time-out or deserved punishment). Conversely, when respondents were directly involved in the act, they were less likely to perceive it as victimization (e.g., "behavioral outburst" instead of a physical assault; "voluntarily giving money” instead of financial deceit or exploitation). This finding indicates the influence of perspective on the likelihood defining acts involving persons with ID as victimization. When ID is implicated, respondents (with and without ID) seemed reticent to perceive of themselves as victims, but were more likely to perceive others as perpetrators. If it is perceived at all, oftentimes victimization involving individuals with ID is reported as an incident rather than a crime (Petersilia, 2001). In these instances, offenses are handled administratively rather than through legal channels (Sobsey, 1994). This is problematic because it suggests that victimization is not as significant when the victim has ID or other disabilities.

When victims with ID are unable to perceive an act of victimization, they are more likely to remain in situations where victimization could occur repeatedly. The likelihood of recurring victimization becomes especially problematic when perpetrators have an intimate affiliation with the victim (Sobsey \& Doe, 1991). As a service provider discussed, these individuals may perceive an act to be forceful instruction or legitimate punishment while an outside observer may perceive the same act to be illegitimate harm or excessive punishment. Furthermore, when they value their relationships with others, people with ID may not perceive significant others as potential or actual victimizers because trust may obscure their awareness that these individuals can cause them harm. This supports the assertion that a failure to report victimization increases the risk of individuals with ID (Petersilia, 2001).

When their environments and encounters are predictable, individuals with ID appear to be better able to detect deviant strangers and precarious circumstances. The results of the current study support prior research that suggests that individuals with ID are more comfortable and have an easier time making decisions in environments and situations that are familiar and predictable (Snell et al., 2009). However, when they are in complex or novel situations, individuals with ID are more likely to be compliant and overly trusting, especially when the other person is in a position of authority. The consequence is that they are more prone to make poor decisions in situations that are unfamiliar to them (Snell et al., 2009). Although predictability appears to reduce the difficulty of decision-making for individuals with ID, as noted above, it also could increase the difficulty of recognizing potential or actual victimizers, particularly when they are family members or significant others. If the individual with ID is unable to identify a victimizer as such, they are more likely to remain in situations where victimization could occur repeatedly.

In order to effectively address the challenges inherent to novel situations as well as the reality that almost anyone could be a potential victimizer, individuals with ID require regular and ongoing training in recognizing and responding to various forms of victimization. Based on information from service pro- 
viders and supervisors, training clients with ID in how to recognize, respond to, and report signs of victimization should be individualized to the capabilities of each individual, conducted on a regular basis, involve real life scenarios, and should include but not be limited to methods of self-defense, recognition of personal space, understanding of personal rights, and procedures for reporting a crime. Training would be empowering for clients with ID who are able to benefit from it. Clients usually receive regular practice with, or at least exposure to, their finances (e.g., paying bills, maintaining financial records), but training also should include personal safety and protection, risk reduction, and violence prevention, and it should take place at home, school, work, and independent living centers (Marge, 2003). Weekly or bi-weekly training in how to recognize and respond to problematic situations could provide familiarity and much needed experience for individuals with ID. Training also must acknowledge an individual's history of victimization because if this is not properly considered, there is a greater likelihood of continued risk for repeated victimization (Marley \& Buila, 2001). Importantly, multiple supervisors explained that training should not be limited to persons with ID alone. All individuals who work with persons with ID as well as concerned family members should participate in the training. In order to lessen their use of harsh methods of compliance such as physical force or coercive punishment, these individuals should be trained in non-forceful methods of dealing with someone with ID.

There are some limitations to this study. Persons with ID that were interviewed functioned toward the higher end of the intellectual disability spectrum given that they were assessed as having mild ID. Those with more severe ID likely deal with significantly different obstacles and may face considerably more risk in their lives. Interviewing a sample of individuals with severe ID would be difficult, but compiling victimization histories from members of this group would give a more complete representation of the risks this population faces. With this population, there were concerns about memory, language comprehension, and possible difficulty being able to fully explicate their responses. However, to understand the perceptions of victimization of individuals with ID, it is important to gather information directly from these individuals because the reality is that individuals with ID are the only people who can understand and convey the totality of their experiences (Stone \& Priestley, 1996; Taylor \& Bogdan, 1998).

An additional limitation is that there was only one female participant with ID in this sample. It is likely that females will experience victimization in a different way than males, and thus it is not possible to draw conclusions based on gender in this study. Finally, service providers and supervisors who volunteered to participate in this study could represent a biased sample.

Future research should include interviews with parents and guardians because depending on how much time they spend together, data from these individuals could provide valuable supplementary information. Research should also explore the most effective methods for training persons with ID and the service providers, case managers, and supervisors who work with them. Information from persons with ID regarding their satisfaction with support services should also be sought. Finally, research needs to focus on the etiology of the abusive and criminal behaviors of perpetrators and how such behaviors can be prevented.

\section{Acknowledgements}

The author thanks Dr. Richard Curtis for his insightful comments on early drafts of this paper. Also, the author dedicates this work to all those who dedicate their lives to serving persons with disabilities.

\section{REFERENCES}

Administration on Intellectual and Developmental Disabilities (n.d.). About the president's committee for people with intellectual disabilities. Washington, DC: Administration on Intellectual and Developmental Disabilities.

http://www.acf.hhs.gov/programs/aidd/programs/pcpid/about

Basit, T. N. (2003). Manual or electronic? The role of coding in qualitative data analysis. Educational Research, 45, 143-154. doi:10.1080/0013188032000133548

Bukowski, W. M., \& Sippola, L. K. (2001). Groups, individuals, and victimization: A view of the peer system. In J. Juvonen, \& S. Graham (Eds.), Peer harassment in school: The plight of the vulnerable and victimized (pp. 355-377). New York: The Guilford Press.

Bushman, B. J., \& Huesmann, L. R. (2001). Effects of televised violence on aggression. In D. G. Singer, \& J. L. Singer (Eds.) Handbook of children and the media (pp. 223-254). Thousand Oaks, CA: Sage Publications.

DeJong, G., Batavia, A. I., \& Meknew, L. B. (1992). The independent living model of personal assistance in national long-term care policy. Generations, 16, 89-95.

Harrell, E. (2011). Crime against persons with disabilities: 2008-2010. Washington, DC: Bureau of Justice Statistics, Office of Justice Programs, US Department of Justice.

Hickson, L., Golden, H., Khemka, I., Urv, T., \& Yamusah, S. (1998). A closer look at interpersonal decision-making in adults with and without mental retardation. American Journal on Mental Retardation, 103, 209-224. doi:10.1352/0895-8017(1998)103<0209:ACLAID>2.0.CO;2

Hiday, V. A., Swartz, M. S., Swanson, J. W., Borum, R., \& Wagner, H. R. (1999). Criminal victimization of persons with severe mental illness. Psychiatric Services, 50, 62-68.

Hill, R., Lewis, V., \& Dunbar, G. (2000). Young children's concepts of danger. British Journal of Developmental Psychology, 18, 103-119. doi:10.1348/026151000165607

Horner-Johnson, W., \& Drum, C. E. (2006). Prevalence of maltreatment of people with intellectual disabilities: A review of recently published research. Mental Retardation and Developmental Disabilities, 12, 57-69. doi:10.1002/mrdd.20097

Khemka, I., Hickson, L., Casella, M., Accetturi, N., \& Rooney, M. E. (2009). Impact of coercive tactics on the decision-making of adolescents with ID. Journal of Intellectual Disability Research, 53, 353362. doi:10.1111/j.1365-2788.2009.01152.x

Loberg, M. E. (2009). Victimization of inmates with intellectual disability: A qualitative study. Doctoral dissertation, Pacific University. http://commons.pacificu.edu/spp/99

Marge, D. K. (2003). A call to action: Ending crimes of violence against children and adults with disabilities. Syracuse, NY: State University of New York, Upstate Medical University.

Marley, J. A., \& Buila, S. (2001). Crimes against people with mental illness: Types, perpetrators, and influencing factors. Social Work, 46, 115-124. doi:10.1093/sw/46.2.115

Marx, B. P., Calhoun, K. S., Wilson, A. E., \& Meyerson, L. A. (2001). Sexual revictimization prevention: An outcome evaluation. Journal of Consulting and Clinical Psychology, 69, 25-32. doi:10.1037/0022-006X.69.1.25

Merriman, S. B. (2002). Qualitative research in practice: Examples for discussion and analysis. San Francisco, CA: Jossey-Bass.

Mishna, F. Scarcell, I., Pepler, D., \& Weiner, J. (2005). Teachers' understanding of bullying. Canadian Journal of Education, 28, 719-738. doi: $10.2307 / 4126452$

Moore, D. (2000). Substance use disorder treatment for people with 


\section{N. EVANS}

physical and cognitive disabilities. Rockville, MD: US Department of Health and Human Services.

Muccigrosso, L. (1991). Sexual abuse prevention strategies and programs for persons with developmental disabilities. Sexuality and Disability, 9, 261-271. doi:10.1007/BF01102396

Nosek, M. A., Foley, C. C., Hughes, R. B., \& Howland, C. A. (1997). Vulnerabilities for abuse among women with disabilities. Sexuality and Disability, 19, 177-189.

doi:10.1023/A:1013152530758

Oktay, J. S., \& Tompkins, C. J. (2004). Personal assistance providers' mistreatment of disabled adults. Health \& Social Work, 29, 177-188. doi:10.1093/hsw/29.3.177

Petersilia, J. (2001). Crime victims with developmental disabilities. Criminal Justice and Behavior, 28, 655-694.

doi:10.1177/009385480102800601

Pimlott-Kubiak, S., \& Cortina, L. M. (2003). Gender, victimization, and outcomes: Reconceptualizing risk. Journal of Consulting and Clinical Psychology, 71, 528-539. doi:10.1037/0022-006X.71.3.528

Powers, L. E., Curry, M. A., McNeff, E., Saxton, M., Powers, J. L., \& Oschwald, M. (2008). End the silence: A survey of abuse against men with disabilities. Journal of Rehabilitation, 74, 41-53.

Quinney, R. (1974). Who is the victim? Criminology, 10, 314-323. doi:10.1111/j.1745-9125.1972.tb00564.x

Rand, M. R., \& Harrell, E. (2009). Crime against people with disabilities, 2007. Washington, DC: Bureau of Justice Statistics.

Sin, C. H., Hedges, A., Cook, C., Mguni, N., \& Comber, N. (2009). Disabled people's experiences of targeted violence and hostility. Manchester, UK: Equality and Human Rights Commission.
Snell, M. E., Luckasson, R., Borthwick-Duffy, W. S., Bradley, V., Buntinx, W. H., Coulter, D. L. et al. (2009). Characteristics and needs of people with intellectual disability who have higher IQs. Intellectual and Developmental Disabilities, 47, 220-233. doi:10.1352/1934-9556-47.3.220

Sobsey, D., \& Doe, T. (1991). Patterns of sexual abuse and assault. Journal of Sexuality and Disability, 9, 243-259. doi:10.1007/BF01102395

Sobsey, D. (1994). Violence and abuse in the lives of people with disabilities: The end of silent acceptance? Baltimore: Brooks Publishing Co.

Stone, E., \& Priestley, M. (1996). Parasites, pawns, and partners: Disability research and the role of the non-disabled researchers. The British Journal of Sociology, 47, 699-716. doi:10.2307/591081

Taylor, S. J., \& Bogdan, R. C. (1990). Quality of life and the individual's perspective. In R. L. Schalock (Ed.), Quality of life: Perspectives and issues (pp. 27-40). Washington, DC: American Association on Mental Retardation.

The Arc (2012). Intellectual disability. Washington, DC: Author. http://www.thearc.org/page.aspx?pid=2543

US Department of Justice (2009). Hate crimes statistics. Washington, DC: US Department of Justice. http://www2.fbi.gov/ucr/hc2009/victims.html

Wilson, C., \& Brewer, N. (1992). The incidence of criminal victimization of individuals with an intellectual disability. Australian Psychologist, 27, 114-117.

doi:10.1080/00050069208257591 